\title{
Review Paper on E-Waste in Concrete as A Replacement of Fine and Coarse Aggregate
}

\author{
Md. Sharfuddin Baba ${ }^{1}$, N Surya Teja ${ }^{2}$, M Siri $^{3}$, B Sai Kumar ${ }^{4}$, M Vishnu Vardhan ${ }^{5}$, G. Lalitha ${ }^{6}$ \\ $1,2,3,4,5$ Dept. of Civil Engineering, VNR Vignana Jyothi Institute of Engineering \&Technology, Telangana, India \\ ${ }^{6}$ Asst prof Dept. of Civil Engineering, VNR Vignana Jyothi Institute of Engineering \&Technology, Telangana, India
}

\begin{abstract}
Civil or Construction Engineering is one of the oldest forms of engineering, and methods followed as were old for a certain time, but when the world was in deep environmental crises, civil engineering came up with many new solutions. Utilization of solid waste and other environmental-unfriendly materials to environmental-friendly materials. But nowadays e-waste is turning out to be a major problem. Like plastic and PCB's which are part of e-waste, is a big threat to the environment when left without treating them. It is creating a great threat to the environment, landfills, and groundwater is becoming toxic day by day. to solve this landfill problem and prevent groundwater from becoming toxic, e-waste was considered as a source of construction. E-waste as replacement either coarse, fine or both aggregate gave amazing results. on further let's see how long will this E-waste concrete sustains and its performances against workability and strength tests in the below papers.
\end{abstract}

Keywords: e-waste, PCB's, environment, strength test, workability test, concrete, landfills.

\section{INTRODUCTION}

The rapidly growing of tech these days, up-gradation of new innovations in tech and the electronics manufacturing industries have led the E-Waste as one of the fastest-growing waste streams in the world. Electronic waste such as Mobiles, iPods Refrigerator, Computers and Printers, washing machines, Televisions. which are harmful to the environment. E-waste produced in India is about 2 million TPA (tonnes per annum). As a civil engineer, we take this opportunity and utilized e-waste as a replacement for aggregate. So, e-waste concrete is evolved in such a process that is lightweight and more flexible.

\section{Sunil Ahirwar et.al}

The waste materials that come from the construction field can also be reused that gives better economic and environmental benefit. Sunil Ahirwar along with his colleagues tried to make the best out of e-waste as they inappropriately found rapid disposal of Electronic-waste. So, they tried the including the e-waste into coarse aggregate replacement. The aim of their study was the investigation of the change in mechanical Behaviour \& Properties of concrete when the addition of E-Waste is done in concrete. The Coarse aggregate is replaced partially by E-waste in $0 \%$ to $30 \%$ proportions. They also included 10, 20, and 30 Percent of flyash partially replacing the cement. As per the tests conducted on various specimens made with different percentage inclusions of e-waste and fly ash as partial replacement of coarse aggregate and cement respectively, they have come to results: $30 \%$ of cement replacement with fly ash along with electronic waste gives the best result. The strength of concrete increased by $17.8 \%$ by the inclusion of $7.5 \%$ e-waste. Many favorable results were obtained like concrete is lightweight and thus the weight of the structure is reduced. Workability was increased as increase in percentage inclusion of e-waste. Makes concrete more flexible and hence bear seismic loads. They concluded that E- waste can be used replace the coarse aggregate somewhere between $10-20 \%$.

\section{2: Manikandan et.al}

Manikandan along with his team focused on the improper disposal of e-waste. In our Country (India), primary source of Electronic waste generated was from public \& private sector which are $70 \%$ from the total waste being generated. The annually estimated generation of E-waste was around $4,00,000$ tons. It is found that most of the e-waste generated is from cities like Bombay, Delhi, Bengaluru, and Madras was estimated approx. 10,000 , 9,000, 8,000 , and 6,000 Tonnes Respectively. only $4 \%$ of total waste generated is recycled per annum, it's a disappointment. So, they made efforts for usage of E-waste components as for partially replacing the coarse(10-12) $\mathrm{mm}$ Aggregate. The major conclusions drawn by them are: Density of Electronic Waste as Replacement of Coarse or Fine Aggregate in concrete is less when compared to Existing Normal or Conventional concrete as resulting in the lightweight blocks emerge which also reduced the cost of concrete blocks. Up to $15 \%$ replacement is allowable as it increased compressive strength and durability compared to conventional concrete.

\section{3: Sagar R. Raut et.al}

Sagar R. Raut along with his team Roshani S. Dhapudkar, Monali G. Mandaokar focused on the replacing the coarse aggregate by electronic waste $\&$ also tried to replace fine aggregates by e-waste. They have mainly focused on the replacement of aggregates but not included fly-ash for partially replacing the cement. The major conclusions that were drawn by them were: $15 \%$ of partial replacing of aggregates gave the best results for Testing of Compression. Electronic Waste can be used as a possible partial replacement for the Coarse Aggregates.

Tensile Strength (Split) was max. at 15 percent partially replacing the coarse aggregate by electronic waste. This Study show the Optimum percentage of replacement.

\section{Lakshmi et al. (2010)}

Lakshmi along with her team, was studying the usage of Ewaste materials for replacing the coarse aggregate. The experiment was done by choosing percentage replacement ranging from $0 \%, 4 \%, 8 \%, 12 \%, 16 \%, 20 \%, 25 \%$ in 
Concrete Grade M20. The Compressive, the Tensile \& Flexural Strength with and without replacing the aggregate with E-waste in Concrete. After the casting, the blocks showed a good gain in strength. The Ultrasonic Pulse tests on mechanical Properties were also executed. At last they concluded that till $20 \%$ replacement of E-Waste was good and increasing the E-waste replacement detiorated the performance. Hence, E-Waste can also be disposed in form of construction materials.

\section{Hamsavathi Et.al}

This research paper speaks about the materials based on EWaste as fillers in order to improve the mechanical Properties of Concrete Structural Members. Therefore both traditional method \& New methods were used in development of the newer concrete cubic samples. Electronic wastes were downsized to around $12 \mathrm{~mm}$ taking help of a electronic shredder. These are the particles which were used for partially replacing the coarse aggregate materials with 0-20 wt.\% ranged gravel to Concrete Grade M25. Study between the conventional concrete and Experimental concrete revealed that the usage of electronic waste as the coarse aggregate or partial replacement was displaying more flexural and compressive strength compared to that conventional regular concrete cubes. When Beam comparison was done, it was seen that the capacity for load carrying was also increased from 426 kiloNewton to 480 kiloNewton, $\&$ the compressive strength of was also improved between $18 \mathrm{~N} / \mathrm{mm} 2-30 \mathrm{~N} / \mathrm{mm} 2$. The Final results further gave them an idea that partially replacing the coarse aggregate with Electronic waste, displays more performance when up to $15 \mathrm{wt} \%$ is added; when further added it decremented the strength in terms of compressive.

\section{P. Krishna Prasanna et al. (2014)}

This paper gave information about E-Waste which should be used as a partial replacement to the coarse aggregate. On utilizing E-Waste particles as coarse aggregate in concrete with a replacement of $5 \%, 10 \%, 15 \%, 20 \%$, and with the addition of $10 \%$ Fly ash. And concrete cubes without ewaste were tested for the Compressive Strength Test, Tensile Strength Test, and Split Tensile Strength Test. And the results obtained gave a brief idea about the strength of concrete got reduced to $33.7 \%$ when coarse aggregate is replaced by $20 \%$ of E-waste and it is reduced by $16.86 \%$. When coarse aggregate was replaced by $20 \%$ of E-Waste plus $10 \%$ Fly ash. They have observed that the Compressive Strength of concrete is found to be favorable when coarse aggregate is replaced by $15 \%$ with E-Waste beyond it, the Compressive Strength gets decreased. They concluded that the use of E-Waste as aggregate gave birth to new concrete which is less in weight as compared to conventional concrete. They have suggested that reusing E-Waste as coarse aggregate in concrete gave a good approach to reduce the cost of materials and solve the e-waste problem.

\section{Needhidasan Santhanam et.al}

Needhidasan Santhanam et al. this paper majorly focused on the partial replacement of the E-waste plastics in place of coarse aggregate, to minimize the pollution $\&$ depletion by reusing the same in the required shape and to understand the behavior of M20 concrete by conducting strength tests on it. In this study we can find that up to $20 \%$ of partial replacement is suggested for optimum performance of concrete. The manufacturing of a new combination of aggregates and binder in concrete partially replacing the aggregate using E-waste were studied. In this project work determination of the compressive strength, tensile strength, and flexural strength of concrete with partial replacement by e-waste for coarse aggregate is done. Volumetric batching was done to mix the materials in required estimated quantities \& to analyze the amount required for the casting of the concrete cubic specimen by considering the Mix as M20 grade (cement: fine aggregate: coarse aggregate) is 1: 1.5: 3 as per IS $383: 1970$ and IS 456:2000 specifications. The coarse aggregate was partially replaced by $0 \%-20 \%$ by weight of the concrete. The mix design was taken from the IS 10262:2009 as a reference from these Concrete mix proportions-Guidelines. Reusability of the E-Waste Plastics as a replacement for the coarse aggregates partially (from 10 - 20\%) is viable in existing conditions without any admixtures and can be the best alternative for the conventional concrete. The Utilization of E-waste plastic aggregate will reduce the unit weight of concrete; hence reduction will be done in the dead weight of the structure. Therefore, it is concluded that it can be used as a block of lightweight concrete. The slump cone value shows the inability of plastic in the absorption of water. The compressive and flexural strength of the E-waste replaced concrete by 28 days decreased when compared to the standard control mix. Splitting tensile strength increased with the increase of E-plastic. The E-plastic wastes which are used from the disposed of wastes have poor shape and smooth surface which have a significant influence on the crispiness \& the behavior of the concrete.

\section{S. Needhidasan et.al}

The main objective of the study is to study the behavior of partially replaced aggregate by the E-waste plastic Concrete $\&$ the minimization of the impact of E-waste on the environment and the re-use of the same to place in required shape and to study the behavior of M40 concrete in presence of Super Plasticiser. The mix design ratio in the manufacturing of concrete was done as per the standards of IS 456:2000 and IS 10262:2009. OPC 53 grade Cement is used during the entire test. Coarse aggregates in the range of 10 to $20 \mathrm{~mm}$ were used in equal weight. The w/c ratio of the mix design was 0.28 and the slump cone value was $50 \mathrm{~mm}$. The relative density of cement, coarse aggregate, and fine aggregate are $3.14,2.71$, and 2.84 respectively and concrete was placed conventionally. The cubes were molded and tested for the compression strength test, Flexural strength test, and Split tensile strength test for 7, 14, and 28 days. The results showed that the properties of fresh and hardened concrete have been improved. Hence, it is concluded that the usage of E-Waste plastic as coarse aggregates partial replacement in concrete by volume $0 \%, 12 \%, 17 \%$, and $22 \%$. The utilization of plastic aggregate in concrete resulted in the reduction of the overall unit weight of concrete and the compressive strength of the concrete was gradually 
increased by the replacement of a different percentage of Eplastic waste.

\section{Santhanam Needhidasan et.al}

This Study mainly focused on the replacing the coarse aggregate between the range of 0 to $12.5 \%$ with electronic plastic waste of Grade M 20 with sand. They Found that the compression capacity or strength of electronic waste concrete is high when compared to normal (or) conventional concrete. For $10 \%$ of Partial replacement, higher flexural strength was observed in comparison to conventional concrete with $10 \%$ replacement of aggregate and the tensile test (Split) is high in comparison to the concrete with $12.5 \%$ replacement of aggregate. The Aim or Objective of this study was the comparison of E-Waste concrete Properties to the conventional \& understanding the behavior, Properties in replacement (Partial) of aggregate. M20 Concrete Mix by the Standard technique used in IS Codes was followed \& Design mix ratio of 1:1.5:3 with a w/c ratio of 0.5 was used. E-Waste plastic was used in partially replacing in a measure of $0,10,12.5$ Percent by Concrete Weight in the Given mix. They concluded that the E-waste can be used as coarse aggregates partial replacement in a Concrete block by volume (0-12.5\%). compressive \& flexural strength of electronic waste concrete decreased as percentage of electronic-waste increased, whereas tensile strength increased in increments of E-Waste plastic.

Puli Sai et.alHere, in this research, E-plastic waste was used in improvement of the structural and mechanical properties of the Concrete Grade M60. This study also focuses on the high strength attributes of concrete with replacement or addition of Electronic plastic waste and partial replacement of coarse aggregate in different percentages of the E-plastic waste was done $(0 \%, 8 \%, 12 \%$, and $16 \%)$ and fly-ash was added as admixture in order to improve the behaviour of the concrete. The specimens of concrete were casted and experimented on them, these experiments were done on the samples the Slump Cone, Compression, Flexural and Split Tensile Strength test. The concrete workability of mixture results is compared from (7-28 Days) of curing. The mix design for high strength concrete M60 was prepared by using the below data. The type of cement used was OPC 53 grade. The Minimum nominal aggregate used was $20 \mathrm{~mm}$. Maximum water/cement ratio 0.28. the specific Gravity of cement was 3.14. the Specific Gravity of the coarse aggregate used was 2.71 . the relative density of fine aggregate was about 2.84. $20 \%$ partially replacing of coarse aggregate is suggestable as more than $20 \%$ causes a decrement in the Concrete Strength. The amount of fly ash content added to the E-waste concrete resulted in an increase of the workability of the concrete \& was performing better than the latter one. Admixture with $20 \%$ fly ash as partially replacing the cement, flexural strength is increased around 2.8 $\mathrm{Pa}$ and 4.2 Pa for $7 \& 28$ days. [19]. The reuse of E-waste will possibly help us in the reduction of disposal of E-waste as well as help in the reduction of solid waste and will save our environment and the harmful effects of pollution. This re-usage of E-waste in the civil engineering field reduces the cost and results in better performance of the concrete.

\section{Sohan Lal Angure et.al}

The E-waste that's left within the lowland releases harmful gases directly or indirectly affects the setting and human health. Utilization of wastes like this for varied functions with facilitates the US shield the setting and avoid pollution. in line with the present study, to organize the coarse combination Plastics was used, that crystal rectifier to associate choice to subsume plastic waste. once studied the impact of victimization e-waste as admixtures the results were satisfactory. nitrate, Triethanolamine, and Trisopropanolamine ar a number of the admixtures used. Disposal of E-waste may be done by victimization as construction materials. It will replace a coarse combination because it cannot replace fine combination. once E-waste content was over two hundredths it was ascertained that the strength perceptibly decreases. two-hundredth of the coarse combination may be replaced by E-Waste because it doesn't show any long damaging effects and its acceptable strength development properties. the foremost vital factor is that the compressive strength of recycled combination may be equal or over that of the natural concrete if ash is added to the mixture as a fine combination replacement. last, we can say that e-waste in concrete is that the most important part of property construction, and it'll additionally increase the strength and sturdiness of concrete. Strength gain at early stages may be done by victimization accelerators with flyash and e-waste in concrete are different proportions.

\section{Tanzeem Shaikh et.al}

E-Plastic is one in all the new waste materials utilized in the concrete trade. It solves the disposal problem of huge amounts of Plastic recycled material. E-Waste Plastic particles are derived from recycled or refurbished electrical and equipment. The strength of the specimen depends on varying percentages $(0 \%, 10 \%, 20 \%, 30 \%$, four-hundredth, and $50 \%$ ) of E-plastic additional to that. use plastic waste to induce new materials like concrete and plastic waste is one in all the foremost useful solutions for taking away the plastic waste. the employment of waste in concrete not solely is economical however its additionally controls disposing issues. during this paper, we tend to see the impact of plastic wastes on various factors of concrete-like modulus of physical property, impact resistance, rending strength, permeableness, etc. When $0 \%, 10 \%, 15 \%$, two-hundredths, and twenty-fifths of plastic waste was utilized in concrete preparation the compressive strengths were twenty-four.22, $22.22,21.11,19.55$, and 17.55 severally. we can see that the strength unbroken decreasing as we tend to add additional plastic. however once $1 / 3,5 \%, 10 \%, 15 \%$, and twohundredths of plastic waste was utilized in concrete preparation the compressive strengths were twenty-six.8, 29, $30,28.5$, and twenty-seven severally. So, from the higher than results, \{we will we can $\}$ conclude that E-plastic waste can replace a number of the aggregates within the concrete mixture which ends in an exceeding reduction of unit weight of concrete which might be used as concrete panels.

\section{Salman Siddique et.al}

The paper primarily focuses on the literature on the employment of e-waste in concrete. impact of e-waste on the 
properties of concrete like compressive strength, split strength, and sturdiness are bestowed. This literature primarily shows important importance within the indisputable fact that sources of natural aggregates have gotten decreasing step by step and therefore the aggregates replacement is that the prime importance. the most strategies used for the disposal of e-waste are: Land Fill burning utilize use Properties of hardened concrete are incontestable that use of E-glass waste in concrete as fine combination replacement. The compressive strength of specimens with four-hundredth E-waste glass is 17 November, 27\%, and forty-third more than management concrete at the ages of twenty-eight, 91, and one year. The split tensile check utilized E-waste in concrete as a rough combination replacement from 1/3 to pure gold. The decrease in strength was ascertained in any respect substitution levels. At twohundredth replacement, the best strength reduction was ascertained. They additionally utilized $100 \%$ ash as mineral admixture that resulted in higher split strength. until the 12tone system replacement of natural aggregates, the split strength was higher than reference concrete. the employment of ash improved the split strength by five hundredth Observation and conclusion E-waste is that the probably viable material to be used as a fine combination to provide sturdy concrete. Its use as a fine combination in concrete can facilitate in assuaging the potential drawback of dwindling natural resources. Its use will facilitate in protecting environmental surroundings.

\section{Vikas Srivastava et.al}

This paper presents a review of oxide fume utilization in concrete production and its impact on the concrete. oxide fume is an associate industrial by-product that's used and experimented to get a stronger and sturdy concrete. it's the pozzolana having an awfully\} giant extent which ends in higher and uniform utilization of lime discharged throughout association of OPC and since of its very fine size, it acts as a filler material in between the cement gel grains. addition of oxide fume reduces workability altogether the mixes and therefore the oxide fume mixes ar sticky and cohesive. The invisibility is improved by adding an oxide fume. Compressive strength: whereas victimization $100 \%$ of oxide fume as cement replacement the compressive strength may be raised. The compressive strength is raised by up to $100 \%$ whereas victimization oxide fume as a cement replacement. The variation of compressive strength at totally different replacement levels of cement by oxide fume is shown within the graph. Tensile Strength: On the addition of oxide fume as SCM, the split strength of concrete is raised by $22-\neg 39 \%$. Flexural Strength: On the addition of oxide fume as SCM. the flexural strength of concrete is raised within the vary of twenty-three - forty-seven. Adding an oxide fume reduces the workability. However, in some cases, it improves the workability. The inclusion of oxide fume will increase the compressive strength of concrete considerably (6-57\%) and therefore the increase depends upon the replacement level. The tensile and flexural strength of oxide fume concrete is sort of just like the referral concrete.

\section{A.A. Dhanraj et.al.}

This paper study speaks regarding AN experimental investigation of concrete by mistreatment e-waste. a radical study has been distributed to look at the thermal and inaudible properties of standard concrete by casting the cube specimen. e-waste things, don't disintegrate or decompose. The increasing usage of electrical \& electronic gear has also created another dangerous waste, can also referred as ewaste. With the neighborhood of fatal chemicals and dangerous substances within the electronic contraptions, the transfer of e-waste is popping into AN ecological and wellbeing dangerous dream. E-waste is presently one of the fastest developing waste streams. systematically, innumerable previous PCs, cellular telephones, TV sets, and radio gear square measure tossed an outsized portion of that either finally end up in landfills or unapproved reusing yards. during this study, inaudible pulse speed takes a look at (UPVT), that is AN unaltered, non-destructive take a look at to see the standard of concrete and natural rocks, is used, wherever the strength And quality of concrete or rock square measure assessed by mensuration the speed of an inaudible pulse passing through a concrete structure or natural rock formation. Through the thermal insulation, the concrete state module is solid for the sizes of $300 \mathrm{~mm}$ X $260 \mathrm{~mm}$ with the variation within the thickness 2 ', 3 ', 4 '' and 5 ''. when the set, the state module is being unbroken within the middle of the closed chamber. The occupancy sensors square measure fastened on the perimeters of the state model to live thermal energy liberation. throughout the experiment, we've got determined to use computer circuit board (PCB) cutting waste (FR-4) as a fine mixture wherever FR-4 may be a grade designation allotted to glass-reinforced epoxy laminate sheets, tubes, rods, and PCB. and also, the crushed blue metals obtained from a neighborhood quarry were used as a Coarse mixture. The additional five-hitter of e-waste is replaced in fine mixture part and 100 percent of ash additional. At last, we tend to detect that the e-waste concrete $U$ issue values square measure over the standard concrete block with an equivalent space and different thicknesses. and that we like e-waste by exchange with fine aggregation portion by five-hitter. By adding FR-4 to the fine mixture, it decreases the load of the concrete and it will offer fine strength and sturdiness like standard concrete.

\section{REFERENCE:}

[1] IJSTE-International Journal of Science Technology and Engineering Sunil Ahirwar: ((MTech scholar, dept. of civil Eng.millennium institute of technology, Bhopal).

[2] Jr. of Industrial Pollution Control (Research article) Manikandan M (SRM University Chennai)

[3] The International Journal of Engineering and Science (IJES) Sagar R. Raut (Department of Civil Engineering, Jagadambha College of Engineering \& Technology, Yavatmal)

[4] R Lakshmi, S Nagan - International journal of environmental ..., 2010 - indianjournals.com.

[5] Green high strength concrete containing recycled Cathode Ray Tube Panel Plastics (E-waste) as coarse aggregate in concrete beams for structural applications. Author links open overlay panel K.Hamsavathia K. SooryaPrakashb V.Kavimanic.

[6] P. Krishna Prasanna, M. Kanta Rao, "Strength Variations in Concrete by Using E-Waste as Coarse Aggregate", International Journal of Education and Applied Research, Volume 4, Issue Spl 2, June 2014. 
[7] Concrete blends with E-waste plastic for sustainable future Needhidasan Santhanam, B. Ramesh, Freddy Khim Pohsnem Department of Civil Engineering, Saveetha School of Engineering, Saveetha Institute of Medical and Technical Sciences, Chennai, India.

[8] The amalgamation of E-waste plastics in concrete with a superplasticizer for better strength S. Needhidasan, C.R. Vigneshwar, B. Ramesh. Department of Civil Engineering, Saveetha School of Engineering, Saveetha Institute of Medical and Technical Sciences, Chennai, India.

[9] Experimental study on the use of E-waste plastics as coarse aggregate in concrete with manufactured sand Santhanam Needhidasan, B. Ramesh, S. Joshua Richard Prabu Department of Civil Engineering, Saveetha School of Engineering, Saveetha Institute of Medical and Technical Sciences, Chennai, India.

[10] Demonstration on the limited substitution of coarse aggregate with the E-waste plastics in high strength concrete Needhidasan, Puli Sai.

[11] A Review Paper on Use of E-Waste in Concrete Sohan Lal Angure1 Dr. Savita Maru2 1PG Student (Computer Aided Structural Designing \& Drafting) 2Professor 1,2Department of Civil Engineering 1,2Ujjain Engineering College Ujjain M.P. India.

[12] ISSN: 2454-132X Impact factor: 4.295 (Volume 4, Issue 3) Available online at www.ijariit.com Replacement of fine aggregate with plastic in concrete.

[13] An experimental investigation on concrete by using e-waste as fine aggregate and enhanced the thermal insulation and ultrasonic properties a.a. dhanraj research scholar, department of civil engineering, sathyabama university, jeppiaar nagar, Chennai, Tamil nadu, India c. selvamony department of civil engineering, psn college of engineering and technology, palayamkottai, tirunelveli, tamilnadu, India a. joshuva school of mechanical and building sciences (smbs), vit university, Chennai campus, Chennai, India.

[14] International Journal of Innovative Research in Science, Engineering, and Technology. An ISO 3297: 2007 Certified Organization. Volume 3, Special Issue 4, March 2014. Nationa Conference on Recent Advances in Civil Engineering (NCRACE2013). During 15-16 November, 2013 Organized by Department of Civil Engineering, North Eastern Regional Institute of Science and Technology, Nirjuli, Itanagar, Arunachal Pradesh, India. Copyright to IJIRSET www.ijirset.com 254 Effect of Silica Fume in Concrete.

[15] international journal of civil engineering and technology (ijciet) volume 8 , issue 12, december 2017, pp. 392-399, article id: ijciet_08_12_045 available online at http://http://www.iaeme.com/ijciet/issues.asp?jtype=ijciet\&vtype =8\&itype=12 issn print: 0976-6308 and issn online: 0976-6316 (C) iaeme publication scopus indexed an experiment investigation on concrete by using e-waste as fine aggregate and enhanced the thermal insulation and ultrasonic properties a.a. dhanraj. 